\title{
Influência de fatores genéticos e ambientais sobre características reprodutivas do rebanho eqüino do Exército Brasileiro
}

\author{
Vinício Aurélio Lagoas Campos ${ }^{1,2}$, Concepta McManus ${ }^{3}$, Beatriz Helena Fuck ${ }^{1,2}$, Luiz Fernando \\ Andrade da Silva ${ }^{1,2}$, Helder Louvandini ${ }^{3}$, Laila Talarico Dias $^{3}$, Rodrigo de Almeida Teixeira ${ }^{3}$ \\ ${ }^{1}$ Mestrando do curso em Ciências Agrárias da Faculdade de Agronomia e Medicina Veterinária, Universidade de Brasília, Cx. Postal 04508 , \\ Brasília-DF, CEP: 70910-900. \\ ${ }_{2}^{2}$ Ministério da Defesa, Quartel Geral, Setor Militar Urbano, Brasília-DF. \\ ${ }^{3}$ Faculdade de Agronomia e Medicina Veterinária, Universidade de Brasília, Cx. Postal 04508, Brasília-DF, CEP: 70910-900.
}

RESUMO - Objetivou-se estimar parâmetros genéticos e fenotípicos para intervalo de partos (IEP), idade ao primeiro parto (IPP), intervalo de gerações (IG), vida útil reprodutiva e distribuição de data de nascimentos na temporada em cavalos de quatro grupos genéticos: Brasileiro de Hipismo (BH), Puro-Sangue Inglês (PSI), Hanoveriano (HAN) e Sem Raça Definida (SRD). Foram avaliadas informações do rebanho do Exército Brasileiro coletadas entre 1977 e 2002. Os fatores fixos incluíram ano e mês de nascimento, idade da mãe, sexo do potro, ano e mês de mensuração e grupo genético. Em geral, os fatores examinados foram fontes significativas de variação para as características reprodutivas, à exceção de número do parto e ano de nascimento da mãe para data de nascimento e de raça para IPP. O valor médio de intervalo de partos (IEP) foi 563,9 dias, com efeito significativo da raça sobre essa característica. Os dados comprovaram tendência de diminuição de IEP à medida que mães jovens foram introduzidas na população. A IPP média foi de 7,17 anos e houve influência significativa do ano de nascimento da égua sobre esta característica. A vida reprodutiva média foi 5,34 anos; a raça BH apresentou o maior valor $(6,70$ anos) e a PSI o menor valor (4,24 anos). O número médio de filhos encontrado no rebanho foi de 22,98 produtos por reprodutor e 3,7 filhos por égua. O IG médio foi de 13,05 anos para machos e 9,99 anos para fêmeas. A data média de parição foi 07 de novembro, com melhora ao longo dos anos. A herdabilidade para as características reprodutivas foi baixa. A substituição mais cedo e o uso de menos PSI podem melhorar as características reprodutivas neste rebanho.

Palavras-chave: correlações genéticas, herdabilidade, idade ao primeiro parto, intervalo de partos

\section{Genetic and environmental effects on reproduction traits of an equine herd of the Brazilian army}

\begin{abstract}
This study aimed to estimate genetic and phenotypic parameters for foaling interval (FI), age at first foaling (AFF), generation interval (GI), reproductive life (RL) and foaling date distribution in equines of four genetic groups: Brazilian Showjumper (BS), Thoroughbred (Th), Hanoverian (HAN) and No Defined Breed (NDB). Data collected from 1977 to 2002 was provided by a Brazilian Army herd. Models used for analyses included the fixed effects of month and year of foaling and measuring, age of dam, foal sex and genetic group. With the exceptions of number of foaling and birth year of dam for foaling date and genetic group for AFF, fixed effects were significant sources of variation for the reproductive traits. The average for FI was 563.9 days and it was significantly influenced by breed effect. There was a trend towards a reduction on FI as younger dams entered the population. The average for AFF was 7.17 years and it was significantly influenced by birth year of the dam. Average reproductive life was 5.34 years. The highest value (6.70 years) was observed for BS and the lowest one (4.24 years) for Th. The average number of foals was 22.98 per stallion and 3.7 per mare. The GI was 13.05 years for males and 9.99 years for females. Heritability estimates for reproductive traits were low. Replacement of dams at younger age and less use of Th may improve the reproductive efficiency of this herd.
\end{abstract}

Key Words: age at first foaling, foaling interval, genetic correlations, heritability

\section{Introdução}

O Exército Brasileiro é composto de 1.815 animais de um total de 2.320 cavalos distribuídos em quase todo o território nacional, com exceção da Região Norte, em diversas unidades militares, em diferentes atividades. Esses animais são utilizados pelo Exército Brasileiro para atividades de patrulhamento e guarda de áreas de fronteira e campos de instrução espalhados pelo território nacional, bem como para cerimonial militar e práticas desportivas como salto, concurso completo de equitação, pólo e adestramento. Para atender a esta gama de empregos, a produção de 
animais com essa versatilidade e adaptabilidade, não só às tarefas, mas também às características dos diversos ambientes espalhados pelo Brasil, torna-se complexa. Além disso, muitas destas atividades estão ligadas, exclusivamente, às Forças Armadas, o que dificulta encontrar animais adequados em outras instituições.

As raças para montaria utilizadas atualmente no Exército são: Brasileiro de Hipismo (BH), Hanoveriano (Han), PuroSangue Inglês (PSI) e Sem Raça Definida (SRD). Ressalta-se que os animais SRD devem atingir um padrão pré-estabelecido para o cavalo do tipo militar, como altura mínima de 1,45 m, bons aprumos, boa capacidade cárdiorespiratória, boa cobertura muscular, medidas lineares harmoniosas e ter como andadura característica o trote, não sendo permitidos cavalos marchadores (DLog, 2002). Para o suprimento de animais para desempenhar o papel atribuído ao cavalo militar no Brasil, uma coudelaria é mantida no município de São Borja-RS para a criação de animais dentro dos padrões desejados. A produção média é em torno de 107 potros por ano. Para manter esse plantel, é fundamental que haja sistemas de produção adequados para produzir animais capazes de se reproduzirem, sem defeitos genéticos ou congênitos. Deve-se, então, investir no controle rigoroso da eficiência reprodutiva e do potencial genético dos reprodutores e das matrizes, além de proporcionar ambiente adequado à manifestação deste potencial. O objetivo neste trabalho foi verificar a influência dos fatores ambientais e genéticos na reprodução eqüina do plantel do Exército Brasileiro.

\section{Material e Métodos}

Foram utilizados dados de eqüinos pertencentes à coudelaria de Rincão, uma organização militar destinada à produção de eqüinos do Exército Brasileiro, localizada no município de São Borja, região oeste do estado do Rio Grande do Sul, fronteira com a Argentina. A unidade foi criada em 1922 e extinta em 1975, sendo recriada em 1987, constituindo-se o único centro de produção de eqüinos do Exército. A coudelaria está situada a 55 $35^{\circ} 00^{\prime \prime}$ de latitude sul e a $28^{\circ} 45^{\prime} 40^{\prime \prime}$ de longitude oeste, com altitude em torno de $130 \mathrm{~m}$ acima do nível do mar. O clima da região, de acordo com a classificação de Köppen, é subtropical úmido tipo $\mathrm{Cfa}$, caracterizado por estações bem definidas, com chuvas bem distribuídas ao longo do ano e precipitação média anual de $1.350 \mathrm{~mm}$.

A propriedade ocupa uma área total de 14.936,74 ha, dos quais 1.200 ha são utilizados para a eqüinocultura e o restante para outro tipo de atividade de produção animal ou vegetal ou como campo de instrução para realização de manobras e treinamentos militares. Por sua localização geográfica e pelo clima predominante, as forrageiras utilizadas foram de clima temperado como aveia (Avena sp.), azevém (Lolium multiflorum) e trevo (Trifolium repens). Aos garanhões ainda foi fornecida uma quantidade diária de alfafa (Medicago sativa). O regime de criação dependeu da disponibilidade de área, ficando entre a estabulação e a semi-estabulação. $\mathrm{O}$ acesso ao volumoso, portanto, foi muitas vezes restrito por essas dificuldades físicas. Os eqüinos foram transferidos entre os quartéis de acordo com a necessidade ou por estarem vinculados a determinado militar que os utiliza em competições hípicas. Os animais receberam tratamento contra endoparasitos três vezes ao ano e a profilaxia incluiu vacinação contra influenza eqüina, tétano, encefalomielite, raiva e adenite eqüina, além de exames semestrais para diagnóstico de anemia infecciosa equina.

A infra-estrutura da coudelaria atende às necessidades da atividade à qual se propõe, possuindo baias e piquetes para os garanhões, piquete-maternidade para fêmeas em dias próximos à parição, pavilhão de baias para mães com potro ao pé, pavilhão de potros desmamados e invernadas com pastagens naturais ou cultivadas.

O plantel de reprodução era composto de 206 matrizes e 15 reprodutores, observando-se que as éguas foram originadas no próprio rebanho ou em outros plantéis. Entretanto, por serem adaptadas à região e possuir genealogia conhecida, a tendência atual é a utilização cada vez intensiva de potras provenientes da coudelaria. Por muito tempo, foram utilizadas fêmeas pertencentes à tropa, que, por não mais se prestarem ao serviço (por problemas diversos, geralmente nos membros locomotores), eram destinadas à coudelaria para reprodução. Os garanhões são oriundos da própria coudelaria ou emprestados por criadores conveniados, assim como o sêmen congelado, quando utilizado.

Os acasalamentos foram feitos por monta conduzida, inseminação a fresco ou com sêmen congelado e monta a campo. Na estação de monta, as éguas foram submetidas a rufião, palpação retal e ultra-sonografia. Aquelas que repetiram cio após inseminação foram destinadas à manada para monta a campo, o que também pode ser o destino de éguas que comprovadamente não se adaptaram à monta induzida ou à inseminação. O descarte de fêmeas foi realizadosegundo seu desempenho reprodutivo. Os potros foram condicionados à doma racional desde o nascimento, sendo desmamados e marcados aos seis meses de idade. Aos dois anos de idade, os machos destinados à tropa foram castrados.

Além da necessidade de monta a campo (dois dos reprodutores ficaram nesta situação), os cruzamentos foram conduzidos de acordo com a raça dos animais, sendo 
direcionados individualmente conforme a genealogia dos animais, dando-se preferência aos acasalamentos exogâmicos para evitar os efeitos depressivos da endogamia e elevar a variabilidade genética do rebanho.

A prática de alimentação no plantel reprodutivo consistiu na oferta de forragem em pastagem, concentrado com $14 \%$ de PB para adultos e $18 \%$ para potros, além de suplementação de alfafa para reprodutores e sal mineral ad libitum.

Foram analisados registros de desempenho de animais Hanoverianos, Brasileiro de Hipismo, Puro-Sangue Inglês e SRD. As características incluíram idade ao primeiro parto (IPP: 391 observações), intervalo de partos (IEP: 1.056), distribuição da data de nascimentos (DJ: 1.479), intervalo de gerações e vida reprodutiva (VR: 399). As análises de variância foram realizadas utilizando-se o programa estatístico Statistical Analysis System (SAS , 1996), pelo procedimento General Linear Model (PROC GLM) e Correlações (PROCCORR).

O modelo utilizado na avaliação dos efeitos citados sobre as medidas lineares foi o seguinte:

$$
\mathrm{Y}_{\mathrm{ijklmno}}=\mu+\mathrm{O}_{\mathrm{i}}+\mathrm{R}_{\mathrm{j}}+\mathrm{M}_{\mathrm{k}}+\mathrm{A}_{1}+\mathrm{MM}_{\mathrm{m}}+\mathrm{AM}_{\mathrm{n}}+
$$

em que: $\mathrm{Y}_{\mathrm{ijklmno}}=$ variável dependente (uma das duas medidas de desenvolvimento); $\mu=$ média geral, associada à variável dependente; $\mathrm{O}_{\mathrm{i}}=$ efeito fixo do $\mathrm{i}^{\mathrm{s} \text { simo }}$ sexo do animal ( $\mathrm{i}=$ macho ou fêmea); $\mathrm{R}_{\mathrm{j}=}$ efeito fixo da jésima raça ( $\mathrm{j}=$ Hanoveriano, Brasileiro de Hipismo, PSI ou SRD); $\mathrm{M}_{\mathrm{k}}=$ efeito fixo do $\mathrm{k}^{\text {ésimo }}$ mês de nascimento $(\mathrm{J}, \ldots, \mathrm{D})$; $\mathrm{A}_{1}=$ efeito fixo do $1^{\text {ésimo }}$ ano de nascimento; $\mathrm{MM}_{\mathrm{m}}=$ efeito fixo do $\mathrm{k}^{\text {ésimo }}$ mês de medição $(\mathrm{J}, \ldots, \mathrm{D}) ; \mathrm{AM}_{\mathrm{n}}=$ efeito fixo do $\mathrm{n}^{\text {śsimo }}$ ano de medição; $\mathrm{e}_{\mathrm{ijklmn}}=$ resíduo aleatório associado a cada observação.

Para estimativa dos componentes de (co)variância utilizados na estimativa de herdabilidade e das repetibilidades, utilizou-se o método de máxima verossimilhança restrita livre de derivadas sob modelo animal. Foram realizados os cálculos de herdabilidade e repetibilidade adotando-se o programa MTDFREML (Multiple Trait Derivate Free Restricted Maximum Likelihood), segundo Boldman et al. (1995) ajustando-se a equação:

$$
\mathrm{Y}=\mathrm{X} \beta+\mathrm{Z}_{1} \mathrm{a}+\mathrm{Z}_{2} \mathrm{pe}+\mathrm{e}
$$

em que $\mathrm{Y}=$ vetor $(\mathrm{Nx} 1)$ de observação do animal; $\beta=$ vetor de efeitos fixos (sexo, mês e ano de nascimento, mês e ano de mensuração, raça, ordem de parição) no modelo, associado à matriz de incidência $X ; a=$ vetor dos efeitos genéticos diretos, associado com a matriz de incidência $Z_{1} ; p e=$ vetor dos efeitos de ambiente permanente da égua, associado à matriz de incidência $\mathrm{Z}_{2}$; e $e$ o vetor de resíduos aleatórios.

\section{Resultados e Discussão}

$\mathrm{Na}$ Tabela 1 encontra-se o resumo da análise de variância das características reprodutivas do rebanho eqüino do Exército Brasileiro. De modo geral, os fatores estudados foram fontes significativas de variação para as características estudadas, exceto número do parto e ano de nascimento da mãe para data de nascimento e raça para IPP.

Existem poucos trabalhos na literatura sobre o intervalo de partos de eqüinos, nos quais as médias relatadas para esta característica variaram entre 364,5 a 597,7 dias (Hevia et al., 1994; Kaseda et al., 1995; Panchal et al., 1995; Marcu et al., 1996; Sabeva, 1996; Pundir et al., 1997; Dias et al., 1998; Cacic et al., 2002 ). O resultado encontrado para a população estudada indica que a média da população está bem acima do ideal, visto que, conforme preconizado por diversos autores (Nagy et al., 1998), o IEP ótimo seria anual, devendo ocorrer manejo intensivo do período pós-parto, considerando o período gestacional relativamente constante e longo na égua (11 meses).

Observou-se efeito significativo de raça sobre a característica $(\mathrm{P}<0,0025)$, sendo a PSI a que apresentou maior IEP (769,6 $\pm 386,8$ dias). O menor intervalo de partos foi verificado entre os animais $\operatorname{SRD}(541,38 \pm 263,88$ dias). Para as raças Brasileiro de Hipismo e Hanoverianos, os IEP foram de $573,02 \pm 311,63$ dias e 746,31 $\pm 425,65$ dias, respectivamente.

A ordem de parto foi outra fonte de variação que influenciou significativamente a duração do IEP, que tendeu a diminuir à medida que se elevou a ordem de partos.

Tabela 1 - Resumo da análise da variância das características reprodutivas do rebanho eqüino do Exército Brasileiro

\begin{tabular}{|c|c|c|c|c|}
\hline & $\begin{array}{l}\text { IEP (dias) } \\
F I \text { (days) }\end{array}$ & $\begin{array}{c}\mathrm{VR} \text { (anos) } \\
R L \text { (years) }\end{array}$ & $\begin{array}{l}\text { DJ (dias) } \\
B D \text { (days) }\end{array}$ & $\begin{array}{l}\text { IPP (anos) } \\
A F F \text { (years) }\end{array}$ \\
\hline $\begin{array}{l}\text { № do parto } \\
\text { Foaling number }\end{array}$ & $\mathrm{P}<0,0001$ & $\mathrm{P}<0,0001$ & NS & - \\
\hline $\begin{array}{l}\text { Ano nasc mãe } \\
\text { Birth year of the }\end{array}$ & $\mathrm{P}<0,0001$ & $\mathrm{P}<0,0001$ & NS & $\mathrm{P}<0,0001$ \\
\hline $\begin{array}{l}\text { Raça } \\
\text { Breed }\end{array}$ & $\mathrm{P}<0,0025$ & $\mathrm{P}<0,0001$ & $\mathrm{P}<0,001$ & NS \\
\hline $\begin{array}{l}\text { Ano de parição } \\
\text { Year of foaling }\end{array}$ & $\mathrm{P}<0,0001$ & $\mathrm{P}<0,0001$ & $\mathrm{P}<0,0001$ & $\mathrm{P}<0,0001$ \\
\hline Média & 563,9 & 5,34 & 02 novembro & 7,17 \\
\hline $\begin{array}{l}\text { Average } \\
\mathrm{R}^{2} \\
\mathrm{CV}(\%)\end{array}$ & $\begin{array}{c}0,28 \\
22,39\end{array}$ & $\begin{array}{c}0,89 \\
23,59\end{array}$ & $\begin{array}{c}0,28 \\
24,34\end{array}$ & $\begin{array}{l}0,89 \\
0,64\end{array}$ \\
\hline
\end{tabular}

Table 1 - Summary of analyses of variance for reproductive traits of an equine herd of the Brazilian army

IEP = intervalo de partos; VR = vida reprodutiva; $D J=$ distribuição dos nascimentos na temporada; IPP = idade ao primeiro parto.

$F I=$ foaling interval, $R L=$ reproductive life, $B D=$ birth distribution; $A F F=$ age at first foaling. 
Esses resultados divergem da afirmação de Marcu et al. (1996), que relataram IEP maior para a segunda parição, embora em seu trabalho tenha demonstrado que o período de serviço foi maior para a segunda parição. Como o intervalo de partos é resultado do somatório do período de serviço e do período gestacional, é importante a observação destes dois fatores no resultado final. Assim, os resultados deste trabalho corroboram os de Nagy et al. (1998), que encontraram intervalos do parto à $1-\underline{a}$ e $2 \underline{a}$ ovulações significativamente maiores para primíparas em comparação às multíparas. Kulisa (1995) também verificou em fêmeas árabes um período gestacional maior para as primíparas. Entretanto, Karadzhov (1997) não observou influência do número de partos anteriores sobre o período do parto à ovulação seguinte, não contribuindo, portanto, para o IEP.

$\mathrm{O}$ ano de nascimento da mãe influenciou significativamente $(\mathrm{P}<0,0001)$ a característica intervalo de partos, comprovando tendência de diminuição do IEP à medida que aumenta o número de mães jovens na população (Figura 1), o que pode ter ocorrido ao longo dos anos pelo fato de terem sido incorporadas ao plantel reprodutivo fêmeas da própria criação da coudelaria, selecionadas para habilidade materna.

Ressalta-se a ocorrência concomitante de melhora no ambiente ao qual as fêmeas foram submetidas. A correlação entre as variáveis foi de $-0,622$, indicando que, à medida que mães jovens foram introduzidas no plantel, o IEP diminuiu, mesmo que a curva tenha evidenciado tendência atual de elevação da magnitude da característica.

Houve também influência significativa do ano de parição $(\mathrm{P}<0,0001)$ sobre o intervalo de partos. Sabendo-se que essa característica é pouco influenciada pelos genes de ação aditiva e considerando-se que a pouca variabilidade genética aditiva tem sido atribuída à ação da seleção natural desde a origem das raças, a maioria dos genes que controlam a fertilidade já se encontrariam em homozigose (Pereira,

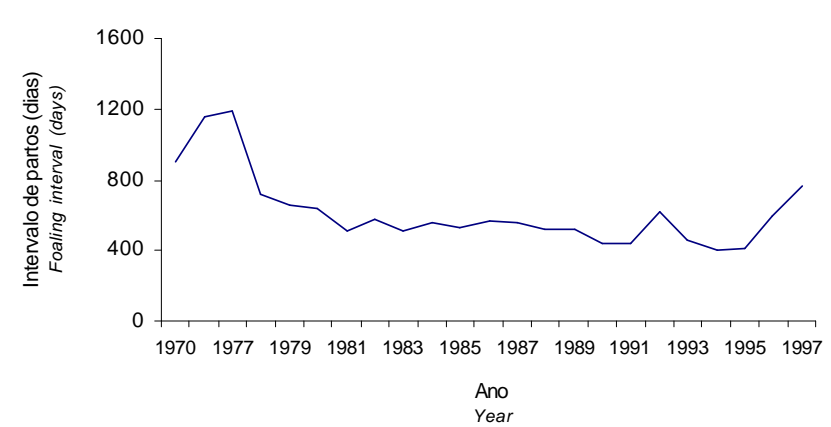

Figura 1 - Efeito do ano de nascimento da mãe sobre o intervalo de partos no rebanho eqüino do Exército Brasileiro.

Figure 1 - Foaling interval trend according to birth year of the dam in an equine herd of the Brazilian army.
1996). Portanto, isto explicaria, em parte, porque esta variação seria efeito de meio ambiente. Observando-se o período analisado, a partir de 1987 (ano de reativação da coudelaria), constatou-se que poucas fêmeas retornaram à reprodução e que o IEP foi elevado, seguindo tendência de aumento de éguas que conceberam até o ano de 1993, quando houve inflexão na curva e diminuição gradativa nos valores de IEP (Figura 2).

Para a idade ao primeiro parto o resultado está distante do ideal para a produção eqüinos (Tabela 1). Por outro lado, a literatura destaca a utilização precoce das éguas na reprodução e suas consequiências. Day (1939) relatou que a idade da égua na sua primeira cobertura determinaria a facilidade de sua prenhêz e poderia ter efeitos potenciais a longo prazo. Davies Morel (2003) mostrou que a idade ideal para as éguas entrarem em reprodução é de 5 a 6 anos, período que terão alcançado tamanho adulto. Na literatura, as médias de IPP variam de 3,36 a 6,88 anos (Hevia et al., 1994; Panchal et al., 1995; Marcu et al., 1996; Pundir et al., 1997; Dias et al., 1998; Cacic et al., 2002).

$\mathrm{O}$ efeito de raça não influenciou significativamente a IPP da população, mas as raças que apresentaram menor e maior IPP foram, respectivamente, Hanoveriana e Puro-Sangue Inglês. Observou-se influência significativa $(\mathrm{P}<0,0001)$ do ano de nascimento da égua sobre a característica IPP, considerando-se registros de fêmeas nascidas entre 1970 e 1997. Como em eqüinos a entrada da fêmea em reprodução muitas vezes ocorre depois de encerrado o período de trabalho ou esporte, o que não diferiu no Exército, tornou-se evidente a adoção desta prática (Figura 3).

A correlação ano de nascimento da mãe $\times$ idade ao primeiro parto foi de $-0,647$, comprovando tendência de maior cuidado na reposição de matrizes, evidenciada pela diminuição da IPP, mais marcante após o ano de 1987 com a reativação do plantel reprodutivo da coudelaria. Como

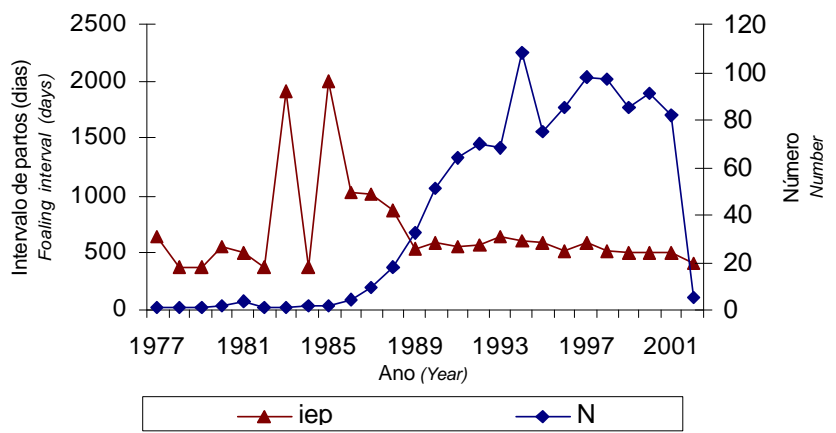

Figura 2 - Efeito do ano de parição sobre o intervalo de partos (IEP) e o número de partos ocorridos no ano (N).

Figure 2 - Foaling interval (FI) and number of foaling/year (N) trends according to year. 


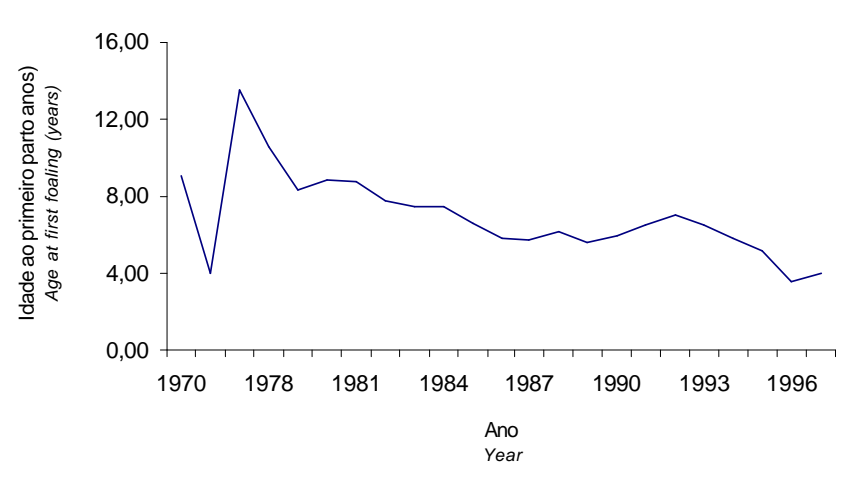

Figura 3 - Efeito do ano de nascimento da mãe sobre a idade ao primeiro parto.

Figure 3 - $\quad$ Age at first foaling trend according to birth year of the dam.

conseqüência da maior atenção aos produtos, houve melhora nas condições de desenvolvimento dos animais. Do mesmo modo, o ano de parição influenciou significativamente $(\mathrm{P}<0,0001)$ a IPP, observando-se que, em alguns anos, muitos animais entraram em produção por necessidade e/ou mudanças na política do Exército, independentemente de sua idade.

Com relação à característica duração da vida reprodutiva, os resultados deste trabalho estão de acordo com os obtidos por Kulisa et al. (1995), que observaram 4,9 anos para a raça Árabe. Entretanto, diferem dos descritos por Hevia et al. (1994), que relataram vida reprodutiva média de 10,93 anos na raça PSI. Davies Morel (2003) destacou a freqüente destinação dos animais à reprodução na espécie eqüina após o tempo de serviço. Conseqüentemente, ficou estabelecida a situação de curtas vidas reprodutivas, particularmente para as fêmeas. A raça do animal influenciou significativamente $(\mathrm{P}<0,0001)$ a duração da vida reprodutiva das fêmeas do plantel: a maior extensão (6,7 anos) foi observada para a raça Brasileiro de Hipismo e a menor $(4,24$ anos) para a PSI. Em fêmeas da raça Hanoveriana, a vida reprodutiva média foi de 5,32 anos e os animais SRD apresentaram média de 4,74 anos.

O número do parto, o ano de nascimento da égua e o ano de nascimento do potro ou o ano de parição influenciaram significativamente a duração da vida reprodutiva $(\mathrm{P}<0,0001)$. Obviamente, animais com mais partos foram mantidos, em geral, por mais tempo no rebanho. Animais nascidos mais próximo do início da criação ficaram mais tempo antes da implantação de normas para o uso dos animais. No mesmo sentido, o ano da parição provavelmente influenciou, pois, ao longo dos anos, foram introduzidos muitos animais advindos da própria criação, agregando eficiência reprodutiva e ocasionando acréscimo na duração da vida reprodutiva à medida que os anos passaram.
O número médio de filhos no rebanho foi de 22,98 produtos por reprodutor, enquanto, para fêmeas, foi de 3,7 filhos por égua. Os reprodutores Hanoverianos tiveram maiores progênies (72,6 filhos por garanhão). Para os animais BH, PSI e SRD, o número de filhos por garanhão foi, em média, de 26; 8,1 e 10,6, respectivamente. Hevia et al. (1994) reportaram na raça PSI número médio de 27,10 filhos por garanhão e 5,47 filhos por égua. Para Hanoverianos, Uphaus et al. (1994) encontraram média de 2,7 filhos por égua. No Brasil, Dias et al. (1998) encontraram 15,2 filhos por garanhão e 2,8 filhos por égua na raça Brasileiro de Hipismo. Para a raça Campolina, Procópio et al. (2003) encontraram 22,2 filhos por reprodutor e 3,1 filhos por égua. Bergman et al. (1997) registraram 10,1 filhos por garanhão na raça Pônei Brasileiro.

O intervalo médio de gerações foi de 13,05 anos para machos e de 9,99 anos para fêmeas, variando por raça (Tabela 2). Para a raça Brasileiro de Hipismo, os dados diferiram um pouco da média encontrada para a raça por Dias et al. (2000), de modo que a média dos garanhões foi de 10,42 anos e a das éguas de 9,31 anos. Uphaus et al. (1994) observaram para a raça Hanoveriana resultados semelhantes para fêmeas, cujo IG médio foi de 9,1 anos, enquanto, para machos, a média foi menor (10,7 anos). Os dados da população em estudo diferiram, ainda, dos valores encontrados por Tunnel et al. (1983) e Procópio et al. (2003) nas raças Quarto de Milha e Campolina, respectivamente, provavelmente em virtude da prática da adoção de animais, particularmente as fêmeas, para reprodução após desempenharem um papel na tropa em atividades de trabalho e/ou esporte. O uso de garanhões de elevada idade também contribuiu para o maior intervalo de gerações nos machos, especialmente na raça Hanoveriana, de modo que reprodutores de

Tabela 2 - Intervalo de gerações de acordo com as diferentes raças do plantel reprodutivo eqüino do Exército Brasileiro

Table 2 - $\quad$ Averages for foaling interval of males and females of different breeds of equines of a Brazilian army herd

\begin{tabular}{lcc}
\hline $\begin{array}{l}\text { Raça } \\
\text { Breed }\end{array}$ & \multicolumn{2}{c}{$\begin{array}{c}\text { Intervalo de gerações (anos) } \\
\text { Generation }\end{array}$} \\
\cline { 2 - 3 } & $\begin{array}{c}\text { Macho } \\
\text { Male }\end{array}$ & $\begin{array}{c}\text { Fêmea } \\
\text { Female }\end{array}$ \\
\hline $\begin{array}{l}\text { Hanoveriana } \\
\text { Hanoverian }\end{array}$ & 14,59 & 9,53 \\
$\begin{array}{l}\text { Brasileiro de Hipismo } \\
\text { Brazilian Show jumper }\end{array}$ & 16,01 & 11,02 \\
$\begin{array}{l}\text { PSI } \\
\text { Thoroughbred } \\
\text { SRD }\end{array}$ & 13,41 & 12,06 \\
No defined breed & 11,79 & 9,54 \\
\hline
\end{tabular}


origem importada foram utilizados durante muitos anos, mesmo após 20 anos de idade.

A raça do animal não influenciou a distribuição dos partos ao longo da estação, obtendo-se médias equivalentes à media do rebanho. $\mathrm{O}$ ano de nascimento da mãe, no entanto, influenciou significativamente $(\mathrm{P}<0,01)$, de modo que os partos das fêmeas acima de 13 anos de idade tiveram data média de nascimentos maior que os das fêmeas com 12 anos de idade ou menos. Isso significa que éguas após a idade reprodutiva mais adequada tendem a ter partos cada vez mais afastados do início da temporada reprodutiva, contribuindo para isso diversos fatores, principalmente falhas no sistema reprodutivo (Vanderwall et al., 1991). O ano de parição influenciou a distribuição dos partos ao longo da estação $(\mathrm{P}<0,001)$. Tomando-se como referencial a melhoria das condições de manejo, que resulta em melhor ambiente a partir de 1996, observa-se que a data de nascimentos do rebanho se afastou, em média, 163,7 dias da data de $1 \stackrel{0}{a}$ de julho (12 dezembro) nos nascimentos ocorridos até 1995. A partir de 1996, os nascimentos se afastaram, em média, 127,3 dias (05 de novembro) daquela data, indicando que melhor manejo promove concepção mais precoce na estação de monta e partos no início da temporada.

Para a raça $\mathrm{BH}$, a estimativa de herdabilidade para IPP foi baixa, como resultado da pequena variância genética aditiva encontrada (Tabela 3 ). Para a distribuição de nascimentos na temporada, a estimativa de herdabilidade foi moderada. Os coeficientes de herdabilidade estimados para IEP foram nulos, indicando que a variação provém basicamente das diferenças ambientais e, conseqüentemente, apenas intervenções no manejo sanitário e nutricional podem promover melhoria nos índices reprodutivos. É possível estar ocorrendo baixa variabilidade genética da raça dentro do rebanho, o que seria prejudicial para a população.

Tabela 3 - Estimativas de herdabilidade $\left(h^{2}\right)$ e ambiente permanente $\left(c^{2}\right)$ das características reprodutivas nas raças $\mathrm{BH}$ e SRD

Table 3 - Heritability estimates $\left(h^{2}\right)$ and permanent environmental effect $\left(c^{2}\right)$ for reproductive traits of the $\mathrm{BH}$ and $S R D$ breeds

\begin{tabular}{lccccc}
\hline $\begin{array}{l}\text { Raça* } \\
\text { Breed }\end{array}$ & & $\begin{array}{c}\text { IPP } \\
A F C\end{array}$ & $\begin{array}{c}\text { DJ } \\
C D\end{array}$ & $\begin{array}{c}\text { VR } \\
R L\end{array}$ & $\begin{array}{c}\text { IEP } \\
C I\end{array}$ \\
\hline BH & $\mathrm{h}^{2}$ & 0,01 & 0,34 & 0,40 & 0,00 \\
& $\mathrm{c}^{2}$ & - & 0,06 & - & 0,81 \\
SRD & $\mathrm{h}^{2}$ & 0,12 & 0,90 & 0,64 & 0,55 \\
& $\mathrm{c}^{2}$ & - & 0,00 & - & 0,28 \\
\hline
\end{tabular}

${ }^{*} \mathrm{BH}$ : Brasileiro de Hipismo (Brazilian Show jumper); SRD: sem raça definida (No defined breed).

IPP: idade ao primeiro parto; DJ: distribuição dos partos na temporada; VR longevidade reprodutiva; IEP: intervalo de partos.

$A F F=$ age at first foaling; $F D$ : foaling distribution; $R L$ : reproductive longevity; FI: foaling interval.
Quanto aos animais SRD, a estimativa de herdabilidade da IPP seguiu o comportamento dos animais BH, com baixa magnitude. Entretanto, foi o grupo que apresentou maior $\mathrm{h}^{2}$ para a distribuição de nascimentos, com grande proporção da variância fenotípica advindo dos efeitos genéticos aditivos. Os animais SRD também apresentaram maior herdabilidade para a longevidade reprodutiva e para IEP em relação aos $\mathrm{BH}$.

Como demonstrado na Tabela 4, a magnitude das correlações para as características de desempenho reprodutivo, quando positiva, não permite afirmar que houve pleiotropismo e que os genes que estão determinando uma característica também definirão o comportamento de outra, especialmente idade ao primeiro parto com distribuição de nascimentos na temporada, intervalo de partos com idade ao primeiro parto, e vida reprodutiva com idade ao primeiro parto e com intervalo de partos

A correlação negativa entre IEP e distribuição de nascimentos na temporada pode ser esperada, visto que, segundo Morel (2002), o mês de nascimento influencia o comprimento do período gestacional e, de acordo com Karadzhov (1997), a estação de parição pode ter efeito sobre o intervalo de partos e a ovulação. Koskinen (1991), avaliando os padrões reprodutivos de 186 éguas no sul da Finlândia, verificou que os nascimentos tardios na estação reduzem o intervalo de partos ao primeiro cio.

De acordo com Bergmann (1993), a utilização do IEP pode ser considerada tendenciosa, pois ocorre apenas em animais com pelo menos dois partos durante sua vida reprodutiva. Além disso, animais que pariram cedo na estação de nascimento podem ter sido forçados a apresentar longo período pós-parto antes da próxima estação de monta e, consequientemente, maior IEP. Por outro lado, matrizes que pariram tardiamente tiveram período mais curto entre o parto e o início da estação de monta e, dessa forma, puderam apresentar IEP menor. Eqüinos são animais poliestro-estacionais e precisam de dias longos para entrar

Tabela 4 - Correlações genéticas entre características de desempenho reprodutivo

Table 4 - Genetic correlations between reproductive performance traits

\begin{tabular}{lccc}
\hline $\begin{array}{l}\text { Característica } \\
\text { Trait }\end{array}$ & DJ & IPP & IEP \\
& $B D$ & $A F C$ & $C I$ \\
\hline IPP & 0,05 & & \\
IEP & $-0,09 * *$ & 0,04 & \\
VR & $-0,10 *$ & 0,02 & 0,01
\end{tabular}

* $(\mathrm{P}<0,05) ;{ }^{* *}(\mathrm{P}<0,01) ;{ }^{* * *}(\mathrm{P}<0,001)$.

$\mathrm{DJ}=$ distribuição nascimentos na temporada; IPP = idade ao primeiro parto; IEP = intervalo de partos; $\mathrm{VR}=$ vida reprodutiva

$B D=$ birth distribution; $A F F=$ age at first foaling; $F I=$ foaling interval; $R L=$ reproductive life. 
em cio. Bourdon \& Brinks (1983) observaram que intervalos de partos curtos são precedidos de intervalos mais longos no próximo ano, fato observado também neste trabalho. Dias et al. (1998) encontraram efeito significativo do regime de luz $(\mathrm{P}<0,01)$ sobre o intervalo de partos, que teve menor valor durante a estação de monta (setembro a março). Entre a vida reprodutiva e a distribuição de nascimentos, também houve correlação negativa. Fêmeas que pariram mais cedo na estação podem ter tido melhor eficiência reprodutiva, permanecendo mais tempo no rebanho.

\section{Conclusões}

As características reprodutivas podem ser melhoradas com a adoção de manejo adequado e a reposição de matrizes que falharam na concepção a fim de diminuir o intervalo de partos.

As médias de idade ao primeiro parto e o intervalo de geração foram superiores ao esperado, evidenciando a necessidade de reposição de reprodutores visando aumentar o ganho genético.

\section{Literatura Citada}

BERGMANN, J.A.G. Melhoramento genético da eficiência reprodutiva em bovinos de corte. In: CONGRESSO BRASILEIRO DE REPRODUÇÃO ANIMAL, 1993, Belo Horizonte. Anais... Belo Horizonte: Colégio Brasileiro de Reprodução Animal, 1993. p.70-86 (supl.).

BOLDMAN, K.G.; KRIESE, L.; Van VLECK, L.D. et al. A manual for use for MTDFREML: a set of programs to obtain estimates of variance and covariance [DRAFT]. Lincoln: Department of Agriculture/Agricultural Research Service, 1995. 120p.

BOURDON, R.M.; BRINKS, J.S. Calving date versus calving interval as a reproductive measure in beef cattle. Journal of Animal Science, v.57, p.1412-1417, 1983.

CACIC, M.; CAPUT, P.; IVANKOVIC, A. Comparison of reproduction characteristics of pure blood Lipizzaner mares and Lipizzaner mares of deficient origin. Stocarstvo, v.56, n.2, p.91-103, 2002.

COSTA, M.D.; BERGMANN, J.A.G.; PEREIRA, C.S. et al. Avaliação dos fatores genéticos e de ambientes que interferem nas medidas lineares dos Pôneis da raça Brasileira. Revista Brasileira de Zootecnia, v.27, n.3, p.491-497, 1998.

DAVIES MOREL, M.C.G. Equine reproductive physiology, breeding and stud management. 2.ed. Wallingford: Cabi International, 2003. 357p.

DAY, F.T. Sterility in the mare associated with irregularities of the estrous cycle. Veterinary Record, v.51, p.1113-1119, 1939.

DIAS, F.J.S.; FALCO, J.E.; LIMA, J.A.F. et al. Influência do fotoperíodo e da temperatura ambiente sobre alguns parâmetros reprodutivos em éguas da raça Mangalarga Marchador em duas regiões do estado de Minas Gerais. Ciência e Agrotecnologia, v.22, n.3, p. 375-383, 1998

DIAS, I.M.G.; BERGMANN, J.A.G.; REZENDE, A.S.C. et al. Formação e estrutura populacional do eqüino Brasileiro de Hipismo. Arquivo Brasileiro de Medicina Veterinária e Zootecnia, v.52, n.6, p.647-654, 2000.
DLog. Normas para o controle dos eqüídeos no exército. Brasília: Ministério da Defesa, 2003. 59p.

HEVIA, M.L.; QUILES, A.J.; FUENTES, F. et al. Reproductive performance of Thoroughbred horses in Spain. Journal of Equine Veterinary Science, v.14, n.2, p.89-92, 1994.

JONES, W.E. Genética e criação de cavalos. São Paulo: Roca, 1987. 666p.

KARADZHOV, T. A comparative study of the factors influencing the independence period duration and the days open duration in mares from Plevenian and Danubian breed. Zhivotnov"dniNauki, v.34, p.239-242, 1997 (suppl.).

KASEDA,Y.; KHALIL, A.M.; OGAWA, H. Harem stability and reproductive success of Misaki feral mares. Equine Veterinary Journal, v.27, n.5, p.368-372, 1995 .

KOSKINEN, E. Reproductive performance in mares in Finland: a study of seasonality, ovulation and postovulatory breeding. Annales Agriculturae Fenniae, v.30, n.1, p.3-39, 1991

KULISA, M.; LUSZCZYNSKI, J. Some factors affecting gestation period of purebred Arab mares at the Michalow stud. Zeszyty Naukowe Akademii Rolniczej im. Hugona Kollataja w Krakowie. Seria: Zootechnika, v.30, p.115-123, 1995.

LAWRENCE, T.L.J.; FOWLER, V.R. Growth of farm animals. Wallingford: Cabi International, 2002. 347p.

MARCU, N.; STATOV, D.; SUSA, M. et al. Main reproductive parameters in Transylvanian horse breeds: I, The value of reproduction indices in Light Draught horses. Buletinul Universitatii de Stiinte-Agricole Cluj Napoca. Seria Zootehnie si Medicina Veterinara, v.50, p.49-56, 1996.

MOREL, M.C.G.D.; NEWCOMBE, J.R.; HOLLAND, S.J. Factors affecting gestation length in the Thoroughbred mare. Animal Reproduction Science, v.74, n.3-4, p.175-185, 2002.

NAGY, P.; HUSZENICZA, G.; JUHASZ, J. et al. Factors influencing ovarian activity and sexual behavior of postpartum mares under farm conditions. Theriogenology, v.50, n.7, p.1109$1119,1998$.

PANCHAL, M.T.; GUJARATI, M.L.; KAVANI, F.S. Study of some of the reproductive traits of Kathi mares in Gujarat state. Indian Journal of Animal Reproduction, v.16, n.1, p.47-49, 1995.

PEREIRA, J.C.C. Melhoramento genético aplicado à produção animal. Belo Horizonte: Universidade Federal de Minas Gerais, 1996. 416p.

PROCÓPIO, A.M.; BERGMANN, J.A.G.; COSTA, M.D. Formação e demografia da raça Campolina. Arquivo Brasileiro de Medicina Veterinária e Zootecnia, v.55, n.3, p.361-365, 2003.

PUNDIR, R.K.; VIJH, R.K.; SHUKLA, R.N. et al. Characterization of Indian Kathiawari horses. Animal Genetic Resources Information, v.21, p.71-80, 1997.

SABEVA, I. Selection aspects of the duration of the period between consecutive foalings in thoroughbred broodmares. Bulgarian Journal of Agricultural Science, v.2, n.6, p.747-751, 1996

STATISTICAL ANALYSIS SYSTEM - SAS. User's guide. Cary: 1996. $595 \mathrm{p}$.

TUNNELL, J.A.; SANDERS, J.O.; WILLIAMS, J.D. et al. Pedigree analysis of four decades of Quarter Horse breeding. Journal of Animal Science, v.57, n.3, p.585-593, 1983.

UPHAUS, H.; KALM, E. Analysis of reproductive factors in hanoverian warmblood population. In: WORLD GENERAL CONGRESS APPLIED TO LIVESTOCK PRODUCTION, 5., 1994, Guelph-Ontario. Anais... GuelphOntario: 1994. p.475-478.

VANDERWALL, D.K.; WOODS, G.L. Age-related ovulatory dysfunction. In: ROBINSON, N.E. (Ed.) Current therapy in equine medicine. Philadelphia: W.B. Saunders, 1992. p.643-644.

Recebido: 19/09/05 Aprovado: 30/08/06 